\title{
Testicular Nasal Type Extranodal NK/T-Cell Lymphoma
}

National Cancer Institute

\section{Source}

National Cancer Institute. Testicular Nasal Type Extranodal NK/T-Cell Lymphoma. NCI

Thesaurus. Code C162468.

A nasal type extranodal NK/T-cell lymphoma affecting the testis. Patients usually present with unilateral testicular enlargement. Bilateral involvement is rare. The prognosis is poor. 